OPEN ACCESS

Edited by:

Huanfa Yi,

Jilin University, China

Reviewed by:

Aung Naing,

University of Texas MD Anderson

Cancer Center, United States

Chenming Sun,

Xian Jiaotong University, China

${ }^{*}$ Correspondence:

Yanling Ma

yanlingma2020@163.com

Specialty section:

This article was submitted to

Cancer Immunity

and Immunotherapy,

a section of the journal

Frontiers in Immunology

Received: 15 August 2020

Accepted: 09 October 2020

Published: 09 November 2020

Citation:

Li Z, Deng J, Sun J and Ma Y (2020)

Hyperthermia Targeting the Tumor

Microenvironment Facilitates

Immune Checkpoint Inhibitors.

Front. Immunol. 11:595207.

doi: 10.3389/fimmu.2020.595207

\section{Hyperthermia Targeting the Tumor Microenvironment Facilitates Immune Checkpoint Inhibitors}

\author{
Zihui Li, Jie Deng, Jianhai Sun and Yanling Ma* \\ Oncology Department, The Third People's Hospital of Hubei Province, Affiliated Hospital of Jianghan University, Wuhan, China
}

Immune checkpoint inhibitors (ICls) have ushered in a new era of cancer therapy; however, ICls are only effective in selective patients. The efficacy of ICls is closely related to the tumor microenvironment. Fever for a long time was thought to directly regulate the immune response, and artificial "fever" from hyperthermia modulates the tumor immune microenvironment by providing danger signals with heat shock proteins (HSPs) as well as subsequent activation of immune systems. Encouraging results have been achieved in preclinical studies focused on potential synergetic effects by combining hyperthermia with ICls. In this review, we summarized a cluster of immune-related factors that not only make hyperthermia a treatment capable of defending against cancer but also make hyperthermia a reliable treatment that creates a type I-like tumor microenvironment (overexpression of PD-L1 and enrichment of tumor infiltrating lymphocytes) in complementary for the enhancement of the ICls. Then we reviewed recent preclinical data of the combination regimens involving hyperthermia and ICls that demonstrated the combined efficacy and illustrated possible approaches to further boost the effectiveness of this combination.

Keywords: hyperthermia, tumor microenvironment, immune checkpoint inhibitors, combined therapy, synergetic effect

\section{INTRODUCTION}

Immune checkpoint inhibitors (ICIs) aim to reverse the immunosuppressive tumor microenvironment (TME) have ushered in a new era of cancer treatment. Efficacy of ICIS-based cancer immunotherapy relies on the immune status in TME. TME is composed of tumor cells, immune/inflammatory cells, stromal cells, blood/lymph vessels, cytokines, secreted proteins, RNAs, and small organelles (1). Through signal transduction and intercellular interactions, TME constitutes and modulates the cancer-immunity cycle (2). Based on the immune status of TME, tumors can be classified as "cold" and "hot" in which "cold" tumors often have a low response rate to anti-PD-1/PD-L1 mAb due to reduced tumor mutation, less T-cell infiltration, less PD-L1 expression and enrichment in immunosuppressive cells (3). Anti-angiogenesis treatment, radiotherapy, or chemotherapy increases the treatment efficacy of ICIs by transforming the immune status of TME through exposure of tumor-specific antigens, normalization of the endothelium, attraction of immune cells, etc. (4-6) Hyperthermia can also modulate the immune status of TME and influence the immune system through cytotoxic effects of high temperatures (7). 
Hyperthermia is a method of killing cancer cells or impeding their growth by increasing tissue temperature with an external heat source for a certain period of time. Hippocrates, the father of modern medicine said, "Those who cannot be cured by surgery can be cured by heat. Those who cannot be cured by heat, they are indeed incurable." Early studies found that fever was correlated with spontaneous tumor regression. Since the last century, hyperthermia has been widely used for patients with both locoregional and advanced cancers in prostate cancer, melanoma, bladder cancer, esophageal cancer, and cervical cancer. The combination of hyperthermia and radio-/ chemotherapy has also shown effectiveness for tumor control in numerous clinical studies. Hyperthermia can be classified as local (microwaves, radio waves, or ultrasound), regional (hyperthermic intraperitoneal chemotherapy), and whole body hyperthermia depending on the organ to be targeted. While based on temperature ranges, hyperthermia can be classified as fever-range temperature hyperthermia $\left(39-40^{\circ} \mathrm{C}\right)$, mild temperature hyperthermia (heat shock temperature, $41-43^{\circ} \mathrm{C}$ ), and thermal ablation (cytotoxic temperature, $>43^{\circ} \mathrm{C}$ ). Magnetic nanoparticle hyperthermia, cryo-thermal therapy, and photothermal therapy are newly developed treatments that also belong to the category of hyperthermia.

Hyperthermia modulates the immune status of tumor microenvironment by providing danger signals with HSPs as well as subsequent activation of immune systems. The immunomodulatory effects not only make hyperthermia a treatment capable of defending against cancer but also make hyperthermia a reliable treatment that creates a type I-like tumor microenvironment (overexpression of PD-L1 and enrichment of tumor infiltrating lymphocytes) in complementary for the enhancement of the ICIs. Below, we summarize a cluster of immune-related factors that are inducible by hyperthermia, highlighting the complementary effect of hyperthermia on immunogenicity and immunoreactivity in the tumor microenvironment for the enhancement of ICIs. Then we reviewed recent preclinical data of the combination regimens involving hyperthermia and ICIs that demonstrated the combined efficacy and illustrated possible approaches to further boost the effectiveness of this combination.

\section{HYPERTHERMIA INCREASES TUMOR DNA DAMAGE}

The $\mathrm{T}$ cell-based immune system frequently responds to neoantigens that arise as a consequence of accumulated DNA damage, known as the tumor mutation burden $(8,9)$. High tumor mutation achieves a higher response rate to PD-1/PD-L1 $\mathrm{mAb}$ and gets a higher objective tumor remission rate. Hyperthermia directly and indirectly induces DNA damage in addition to interacting and interfering with various DNA repair cascades, all of which contribute to mutations in the tumor genome and the production of neoantigens $(8,10)$. Briefly, hyperthermia can directly induce the DNA damage response by promoting single stranded break (SBS), double stranded break
(DBS), histone $\mathrm{H} 2 \mathrm{AX}$ with phosphorylated C-terminal serines $(\gamma$-H2AX) foci formation and ataxia-telangiectasia mutated protein(ATM) phosphorylation and decelerating DNA replication and repair (downregulate DNA polymerases and topoisomerases activity), and indirectly activate DNA damage response and induce tumor suppressor alternative reading frame (ARF) by promoting ROS production, cell cycle arrest, cell cycle checkpoint arrest, cell death, decelerate DNA replication. Moreover, hyperthermia can significantly promote DNA damage in tumor stem cells that are resistant to most classical treatment regimens, which would be more effective for the formation of tumor neoantigens (11). In addition, exosomes extracted from heat-stressed tumor cells (HS-TEX) induce a bystander effect that can transform DNA damage from heatstressed tumor cells to the non-heated ones (12). The enhanced irreversible cellular DNA damage accumulation was further proven by that hyperthermia is applied as a complement in treatment combining chemotherapy or irradiation to induce irreversible cellular DNA damage (13). Nevertheless, the identification of neoantigens requires the mapping of tumorspecific genetic aberrations using whole-exosome sequencing, in silico predictions, mass spectrometry, and T cell assays (9).

\section{HYPERTHERMIA IS A STRONG ICD INDUCER}

Despite mutations and neoantigens for the potential initiation of immunity, only immunogenic characteristic defined by immunogenic cell death (ICD) triggers an immune response. ICD is a novel concept that has emerged during the last decade. ICD depends on the concomitant generation of reactive oxygen species (ROS, Type I) and activation of endoplasmic reticulum stress (ER stress, Type II) $(14,15)$ to function as "enabler" and "eat me" signals to recruited immune cells (16-18). ICD has emerged as an important sign of a favorable immunogenic TME that provides the various functional immunological cell infiltration and cytokines $(15,19)$. Clinical studies have suggested that pre-treatment with ICD inducers sensitizes cells to immune checkpoint blockade treatment (20). Though discussed frequently, hyperthermia is a kind of ICD inducer. Below, we will discuss hyperthermia-induced ICD from two aspects including ICD-related biological events (ER stress, ROS, and apoptosis) and the accompanying generated damageassociated molecular patterns (DAMPs) with an emphasis on HSP.

\section{Hyperthermia-Induced ICD Depends on ER Stress and ROS}

"Fever"-induced apoptotic, necrotic, or even live cancer cells constitute a relevant natural mode of tumor-associated antigen (TAA) $(21,22)$. Hyperthermia generates different modes of TAA depending on the temperature change. Generally, temperature at the fever range $\left(37-41^{\circ} \mathrm{C}\right)$ leads to a protective function for cancer cells with presentation of their constituents, while temperatures of $41-43^{\circ} \mathrm{C}$ promote cell death predominantly by 
apoptosis with a balance between pro-apoptosis and antiapoptosis. As temperature rises even higher, the pro-apoptosis becomes dominant. While temperatures rise above $43^{\circ} \mathrm{C}$ (thermal ablation range), tumor cells experience the destruction mainly by necrosis (23).

Thermal ablation induced necrosis is a pathologic cell death that can produce immunogenic inflammatory response (24). Unlike thermal ablation, fever range hyperthermia can only influence cell membrane fluidity and stability, change cell morphology, and influence intracellular sodium-calcium levels (25). At this temperature, the heat shock response and ER stress can occur simultaneously. Heat shock response-induced HSPs can either diminish the activation or relieve ER stress by activating a negative feedback system of the unfolded protein response (UPR) to avoid excessive activation (26) and can protect tumor cells against both caspase-dependent and caspase-independent apoptosis triggered by oxidative stress (27). Additionally, eIF $2 \alpha$ phosphorylation, the hallmark of $\operatorname{ICD}(28,29)$, was rarely induced at this temperature (30). While temperature rises between the "fever range" and "thermal ablation range" at $41-43^{\circ} \mathrm{C}$, tumor cells died predominantly by apoptosis with a balance between proapoptosis and anti-apoptosis. This process involves the induction of CHOP, the alterations in calcium levels and the activation of ER proteases, calpain-calpastatin proteolytic system and caspase mediated apoptosis $(30,31)$. This process also accompanies with the upregulation of eIF $2 \alpha$ phosphorylation. While both low $\left(43^{\circ} \mathrm{C}\right)$ and high $\left(45^{\circ} \mathrm{C}\right)$ hyperthermic exposures were capable of inducing cell death by activating apoptotic pathways, mild hyperthermia $\left(43^{\circ} \mathrm{C}\right)$ triggers the apoptotic response in a more regulated manner in order to sustain apoptotic cell death (31).

Traditional view holds that apoptosis is non-immunogenic and does not induce an inflammatory response. However, recent studies have suggested that certain kinds of treatment that induce tumor cell apoptosis can also release DAMPs and induce ICD. Calreticulin (CRT) exposure, high mobility group box 1 (HMGB1) release, and adenosine triphosphate (ATP) secretion are essential factors for cell death to be considered ICD (32). In fact, heat-shock conditioning of cancer cells increased their CRT plasma membrane translocation and induced the release of HMGB1 protein. Moreover, both CRT and HMGB1 mobilization were associated with enhanced antigen crosspresentation and antigen present cell maturation after hyperthermia at mild temperature range of $41-43^{\circ} \mathrm{C}(33,34)$. It remains to be elucidated that hyperthermia related apoptosis can induce ICD, but apoptosis induced by hyperthermia is involved in the ICD generation (35-37). Nevertheless, considering the ICD-related biological events of ER stress, ROS, and apoptosis and the accompanying generated DAMPs, hyperthermia can be regarded as an ICD inducer as well as other treatments $(32,38)$. Whereas, it should be noted that hyperthermia-induced ER stress or apoptosis is fostered by focused ROS rather than by secondary or collateral ER stress effects, which were thought to be more effective for ICDassociated immunogenicity (15). Moreover, this referred ICD is different from pathologic necrosis cell death caused by tumor ablation (39).

\section{HSPs Are Among the Most Important DAMPs Induced by Hyperthermia}

Hyperthermia induces various kinds of DAMPs, including HMGB1, CRT, and ATP. In addition, study by proteomic profiling found quantitative proteins regulated by heat shock treatment that can be described as potential DAMPs or candidates for further immunological analysis (40). However, the current paradigm of the immunogenicity of hyperthermia mainly relies on HSPs and activated Toll-like receptor-4 (TLR-4) signaling pathways for the initiation of tumor-specific immune responses $(38,41)$. Here, we discuss various forms of HSPs and the suitable temperature for maximized immunity.

HSPs are a group of highly conserved chaperone proteins synthesized under pressure in a wide range of tumor cells containing HSP70, HSP60, HSP90, and small HSPs. Elevated HSPs are usually associated with poor prognosis in most cancer types. However, these overexpressed HSPs after hyperthermia are also associated with enhanced immune response. There are three forms of HSP: intracellular, membrane, and extracellular HSPs. Intracellular HSPs promote the maintenance of the innate structures and functions of their client proteins by facilitating protein folding when the cells are under homeostatic challenges (42). Unlike intracellular HSPs, studies found that small fractions of several heat-stress cognates are located at or near the cytoplasm inside the membrane along with cytoskeletal proteins, and that additional submembranous localization of HSPs may be a part of cellular responses to heat that associated with membrane damage (43). Whereas, later research found that this membrane HSP70 might also serve as a tumor-specific target for the cytolytic attack of CD56 bright/ $\mathrm{CD}^{+}{ }^{+}$natural killer (NK) cells $(25,44)$. While, extracellular HSPs released from tumor cells are regarded as potent adjuvants to facilitate the presentation of tumor antigens and the induction of anti-tumor immunity $(45,46)$.

In accordance with relationship between biological events and temperature, HSPs start to release at $41^{\circ} \mathrm{C}$ and reach a maximum at $43^{\circ} \mathrm{C}$ but begin to diminish at $45^{\circ} \mathrm{C}(47)$. To achieve the optimal extracellular HSP synthesis for anti-tumor immune activation, Lin et al. developed a model to predict the optimal temperature and exposure time by involving factors such as different cell lines, cell incubation times, and heat administration methods into the model. They found that the maximum extracellular HSP synthesis was at $43^{\circ} \mathrm{C}$, so was the maximum modulatory effect for tumor regression and decreased metastasis. When the temperature was further increased, HSP synthesis decreased, and the immune modulatory effect of hyperthermia was also downregulated (48). Whereas, through bioinformatic approach, Duzgun et al. identified a series of molecules that determine the thermoresistance and immunogenic cell death in thermotherapy through estimating the percentage of the two kinds of denatured proteins. They found that thermoresistance along with ICD both existed in a broad temperature windows, and that average $T_{\mathrm{m}}$ (50\% of the protein is unfolded) of DAMPs 
$\left(63.42^{\circ} \mathrm{C}\right)$ is remarkably higher compared to the thermal ablation temperature due to the function to interact with their pattern recognition receptors (PRRs) even under thermal stress (49). Although the suitable temperature for maximized immunity remains unclear, these models offer ways to rationally explore suitable conditions to exploit hyperthermia.

\section{HYPERTHERMIA ENHANCED THE IMMUNE RESPONSE IN MULTIPLE STEPS}

With increased tumor mutation burden and ICD, immunity is either activated or enhanced by hyperthermia for the subsequent immune response in multiple steps of the cancer-immunity cycle. Hyperthermia-activated immunity appears to be specific, persistent, and memorable. This activated immunity not only makes hyperthermia a capable treatment to defend against cancer but also orient it as a reliable treatment that can facilitate the efficacy of ICIs.

\section{Hyperthermia Promotes APCs' Activation}

It has been established for years that mild thermal stress regulates DCs' activities to control infections and tumor growth $(50,51)$. Although APCs' activation is not directly associated with the prognosis of $\mathrm{PD}-1 / \mathrm{PD}-\mathrm{L} 1 \mathrm{mAb}$ treatment, APCs' activation directly influences tumor-specific $\mathrm{T}$ cell responses. APCs' activation includes antigen presentation and APC maturation. During the process of antigen presentation, hyperthermia mainly regulates "phagocytosis checkpoints" by enhancing the immunogenic "eat me" signals and repressing tolerogenic "eat me" signals as well as "do not eat me" signals (52). Specifically, phagocytosis of APCs is mainly enhanced by immunogenic "eat me" signals of DAMPs through receptor-mediated endocytosis via PRR. Moreover, hyperthermia represses the "do not eat me" signal through decreasing the expression of CD47 in the cell surface (53). In addition, hyperthermia can also inhibit tolerogenic "eat me" signals by transforming immature APCs and/or APCs exhibiting immunosuppressive phenotypes (M2 macrophages, N2 neutrophils, myeloid-derived suppressor cells) to a relatively mature one $(54,55)$. This transformations include infiltrating activated monocytes into the tumor microenvironment (56), inducing immature DCs to differentiate into DCs (45), promoting macrophage polarization to the M1 type that exerts pro-inflammatory effects, and promoting the release of inflammatory factors $(57,58)$. In fact, significantly increased phagocytosis rates of macrophages and DCs have been seen; moreover, this process seems to be temperature sensitive $\left(>43^{\circ} \mathrm{C}\right)$.

Along with antigen presentation, APCs initiate a process of maturation by increasing the expression of MHC I, MHC II molecules and costimulatory molecules, and migrating to the draining lymph node. This process can be mediated by antigen presentation, TLR agonists, the standard maturation cocktail of pro-inflammatory cytokines (59), and physiological temperature stress of $40-41^{\circ} \mathrm{C}(50,51)$. Traditional views hold that hyperthermia-induced ICD is among the strategies to improve the efficacy of dendritic cell-based immunotherapy for specific cancer types (60). However, studies have suggested that merely heating tumor cells cannot activate immature DCs. Only when tumor cells and immature DCs are both under sequential hyperthermia treatment, can the immature DCs be effectively activated. This result suggests that DCs' maturation not only depends on danger signals with HSPs but also on hyperthermia itself independently (61). Further studies proposed that feverrange hyperthermia promote DCs from a quiescent status to an activated status by promoting the metabolic reprogramming in them $(62,63)$. The authors proposed that hyperthermia increased the expression of insulin-like growth factor binding protein 6 (IGFBP-6) and HSP70, whose autocrine mechanism increases the glycolysis, decreases the activity of the mitochondrial respiratory chain and consequent oxidative phosphorylation (OxPhos), enhances the production of NO and ROS, and promotes the mitochondrial $\mathrm{Ca}^{2+}$ overload. It should also be noted that this metabolic reprogramming of DCs functions more like a kind of checkpoint in DCs' activation or maturation, and this process is an early event for the accomplishment of cell-specific immunologic adaptation.

\section{Hyperthermia Corrects Dysfunctional CD4 T Cell Immune Response}

CD4 $\mathrm{T}$ cells display a large degree of plasticity to differentiate into Th1, Th2, Th17, and regulatory T cells (Tregs) in response to different tumor environments $(64,65)$. Th1 cells along with its generated chemokines exert prominent anti-tumor activity by blocking the formation of new blood vessels as well as promoting recruitment of tumor-killing immune cells. Intra-tumoral FoxP3 + Tregs impede effective immune response against cancer and impaired the efficacy of PD-1/PD-L1 mAb. In contrast to function of Tregs, Th17 cells may be prominent candidates for adoptive T-cell therapy (66-68). Functional systemic CD4 T cell immunity is essential for effector cytotoxic T lymphocyte (CTL) priming, memory CTL development, and effective PD-1/PD-L1 blockade $(69,70)$. Hyperthermia showed the potential of correcting dysfunctional CD4 T cell immune response by drifting CD4 T cells to Th1 and transforming Treg cells into Th17 cells to rebuild a favorable TME that can effectively respond to anti-PD-1/PD-L1 mAb.

DC maturation induced by thermal therapy is a prerequisite for CD4 $\mathrm{T}$ cell differentiation $(57,71)$. Besides fever-range hyperthermia $\left(39-40^{\circ} \mathrm{C}\right)$ inhibits Th2 and Treg growth, induces spleen Th1 and Tc1 proliferation, and promotes Th1 cellassociated secretion of IL-2, IFN- $\gamma$ and TNF- $\alpha$ in spleen (72). While cryothermal therapy not only reduced the percentage of Tregs and myeloid-derived suppressor cells (MDSCs) in spleen, lung and blood but also promoted $\mathrm{CD}^{+}{ }^{+} \mathrm{T}$ cell's differentiation into predominant $\mathrm{CD} 4^{+} \mathrm{CTL}$, Th1, Th2, and Tfh subsets (73). Moreover, compared with radiotherapy alone, combined radiotherapy with hyperthermia regulated the tumor microenvironment and upregulated the Th1/Th2 ratio (74). In addition, HS-TEX can elicit Th1-polarized immune responses by increasing the production of IgG2a and IFN- $\gamma$ in sensitized tumors (75). Besides, preclinical studies have shown the potential of hyperthermia to promote Th1-related immunity and repress the 
function of Treg cells. Last, the correcting of dysfunctional CD4 T cell by hyperthermia has also been proven by that patients with tumor treated with hyperthermia showed increases in Th17 cells and decreases in Tregs in the peripheral blood (76).

\section{Hyperthermia Creates a Favorable Inflammatory Tumor Microenvironment}

It is highly dependent on cytokines and chemokines for "cold" tumors with low response rate to PD-1/PD-L1 mAb to transform to a "hot" one that is infiltrated with immune cells in tumor sites. Serum cytokine analysis revealed that hyperthermia at $41^{\circ} \mathrm{C}$ for 30 min induces an intratumoral inflammatory cytokines and chemokines to increase in enhanced T-cell trafficking (77). Specifically, mild hyperthermia increases the expression of Lselectin, P-selectin, and intercellular cell adhesion molecule-1 (ICAM-1) in the vessel wall (78-80) and drives the production of a number of pro-inflammatory cytokines and chemokines (i.e. interleukin-1 $\beta$, IL-6, IL-8, IL-10, and CCL22) (77, 81). This inflammatory cytokines and chemokines act at multiple discrete steps that favor lymphocyte infiltrate to the tumor microenvironment and attack solid tumors in the immune cascade.

Among cytokines and chemokines induced by thermal stress, IL-6 plays a pivotal role in the tumor immune microenvironment. Specifically, cryo-thermal therapy-induced IL-6-rich acute proinflammatory response promotes DC phenotypic maturation, CD4(+) $\mathrm{T}$ cell differentiation, and Th1 anti-tumor immunity $(71,82)$. In addition, hyperthermia induces M1 macrophages to secrete CXCL10 and IL-6 to induce CD4 T cell differentiation into Th1 and CD4 CTL cells, and reduce MDSC aggregation (57). Moreover, IL-6 stimulated by HS-TEX promotes Treg transformation to Th17 cells and induces CD4 T and CD8 T cell-dependent immune responses (76). Though IL-6 also drives tumor growth and promotes survival of neoplastic cells, these tumor-promoting activities are completely counteracted by the effect of T lymphocyte infiltration into the tumor site with a result of tumor cell killing and tumor regression $(81,83)$. However, most of the research was conducted under physiological temperature stress of $40-41{ }^{\circ} \mathrm{C}$. Moreover, hyperthermia alone seems insufficient for tumor cell regression for the result that combination of an artificial cytokine storm and hyperthermia rather than hyperthermia itself can effectively promote the antitumor response (84).

\section{HS-TEX Extracted After Hyperthermia Acts as Tumor Vaccine}

Exosomes are small membrane vesicles of endocytic origin that have a typical bilayer-membrane structure shuttling from donor cells to recipient cells to communicate and transport information between different cells. In response to a variety of stress conditions, cells employ extracellular vesicle to transmit a prosurvival message in the tumor microenvironment for evasion of cell death and transmitting resistance to therapy (85). Heat stress not only promotes the release of TEX (quantity) (86) but also promotes TEX to pack with more positive immunomodulators (HSP70, adhesion molecules, chemokines) rather than negative regulators (fasL, TGF- $\beta$ ) (87).
HS-TEX is a reliable tumor vaccine for tumor-specific immune response. A study suggested that HS-TEX extracted from ascites of gastric cancer can induce DCs' differentiation and promote tumor-specific immune response (88). Whereas, intra-tumoral injection of HS-TEX derived from colon cancer cells and B lymphoma with hyperthermia efficiently induced tumor-specific anti-tumor immunity in mouse models $(89,90)$. Besides, HS-TEX can activate DCs to release IL-6 to trigger subsequent transformation of the immune microenvironment to reduce Tregs and promote the chemotaxis of $\mathrm{T}$ cells to tumors (76). Contents in the HS-TEX plays an important role for its function in TME. HSP-70 abundant exosomes recruit more NK cells and promote the killing of $\mathrm{NK}$ cells better than that of apoptotic fragments and HSP-70 knockout exosomes (91). Chemokines in HS-TEX recruit and activate DCs and tumor-specific $\mathrm{T}$ cells through a lipid raft-dependent pathway to promote tumor immune response. Despite the promising role of HS-TEX in TME, a study also suggested a bystander effect induced by HSTEX from tumor cells that promotes the survival of unstressed ones (12). Moreover, PD-L1 can also express in TEX for immune evasion, but this expression cannot be neutralized by anti-PD-L1 $\mathrm{mAb}$ treatment (92). The sophisticated role of HS-TEX in the TME remains to be elucidated in vivo rather than as a vaccine. (Thus, this part is presented in Figure 1 marked with dotted lines.)

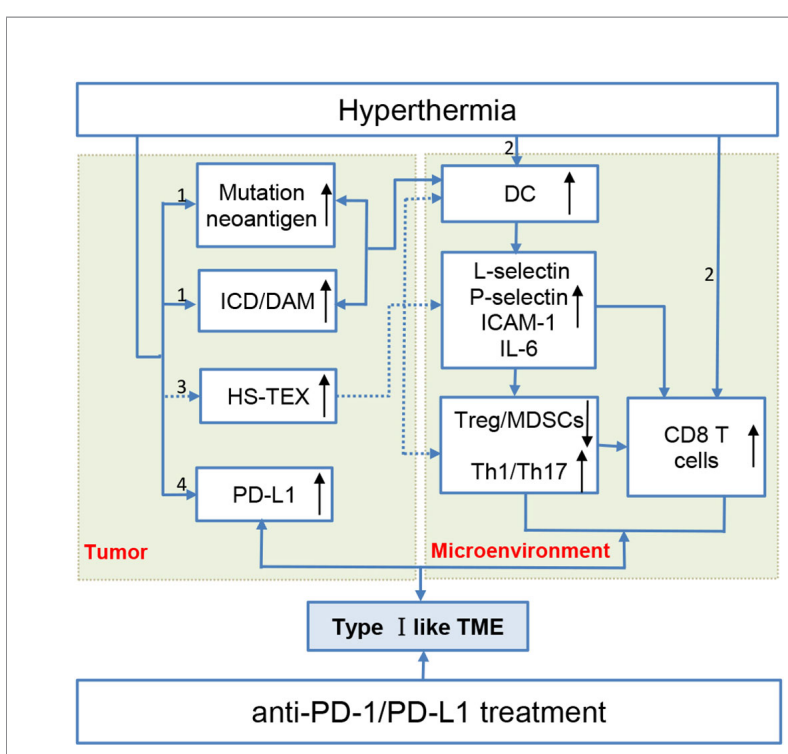

FIGURE 1 | Hyperthermia creates a type I-like tumor microenvironment, and the multifaceted mechanisms make hyperthermia a potent immune checkpoint inhibitor sensitizer. (1) Hyperthermia increases the tumor mutation burden/neoantigen and promotes immunogenic cell death. These two aspects promote DC activation maturation and thus transform the immunosuppressive microenvironment by inhibiting Treg cells and promoting tumor-infiltrating lymphocyte recruitment. (2) Hyperthermia can directly promote DC and T cell maturation. (3) Exosomes extracted from heatstressed tumor cells (HS-TEX) act as a cancer vaccine to activate DCs and promote cells to secrete IL-6 to transform the immunosuppressive TME (marked with dotted lines) (4) Hyperthermia can upregulate PD-L1 expression in an elevated temperature. 


\section{Hyperthermia Promotes CD8 T Cell's Quantity and Quality}

Despite the presence and activation of several immunologic components in the TME, tumor cells are not easily eradicated (93). Mechanisms involved in this impaired response are attributed to the immune suppressive agents in the TME, including the depletion of naïve anti-tumor $\mathrm{T}$ cells during thymic lymphocyte development, unresponsiveness of CTLs due to impaired of costimulatory or enhanced coinhibitory molecules, prolonged presence of immunosuppressive cells and along with secreted inhibitory molecules from those cells (94). Consequently, although immune cells are found in the TME, they are not fully effective $(95,96)$. Hyperthermia can break this barrier by promoting antigen-specific naive CD8 $\mathrm{T}$ cell differentiation, enhancing the cytotoxic potential of $\mathrm{T}$ cells and promoting memory stem $\mathrm{T}$ cell generation.

CD8 T cells' differentiation and function of cytotoxicity are both temperature-sensitive events. Study researched the number of Melan-A/Mart-1-specific CD8 T cells in patients after isolated limb perfusion with hyperthermia and found a small increase in tumor-specific T-cells in a subpopulation of patients with melanoma, demonstrating the potential of thermal therapy in the activation and differentiation of immune effector cells in the tumor microenvironment (97). Another study showed that heatshocked pre-treated melanoma cell lysates promote the proportion of a prototypic effector $\mathrm{T}$ cells $\left(\mathrm{PD}-1^{\mathrm{lo}} \mathrm{CD} 8 \mathrm{~T}\right.$ cell) in the TME to prevent dysfunctional T-cell accumulation and inhibit tumor growth (98). The result that hyperthermia promotes naive CD8 T cells' differentiation are also proved by a study that $\mathrm{CD} 8+\mathrm{T}$ cells under heat stress $\left(39.5^{\circ} \mathrm{C}\right)$ can differentiate into effector cells by reversible clustering of GM1(+) CD-microdomains in the plasma membrane, clustering of TCR $\beta$ and the $\mathrm{CD} 8$ coreceptor, and enhancing the rate of CD8+ T cell-APC conjugate formation in all spleen, lymph nodes, and peripheral blood $\mathrm{T}$ cells. While during the phase of cytotoxicity, the ability IFN-gamma production and cytotoxicity effect of effector CD8+ T cell are also enhanced after hyperthermia $(99,100)$. The enhanced cytotoxicity effect is associated with the expression of HSF1 that upregulates fas ligand expression by translocation of the transcription factors AP-1 and NF- $\kappa$ B (101). Some researchers believe that exhaustion of CTLs is due to impaired formation of memory $\mathrm{T}$ cells (102). Studies have shown that hyperthermia induces differentiation of $\mathrm{CD}^{+} \mathrm{T}$ cells into memory stem $\mathrm{T}$ cells $\left(\mathrm{T}_{\mathrm{SCM}}\right)$ (103) and could possibly redistribute the memory $\mathrm{T}$ cells of patients with tumor (104). Thus based on the results of enhanced T-cell trafficking and promoted CD8 $\mathrm{T}$ cell immunity, hyperthermia can effectively target at the TME to edit the immunity for cancer treatment.

\section{HYPERTHERMIA PROMOTES THE EXPRESSION OF COINHIBITORY MOLECULES}

Despite the reliable effects of hyperthermia on the immunogenicity and immunoreactivity of tumors, hyperthermia can also upregulate the expression of coinhibitory molecules. Studies have shown that heating in the range of $37-49^{\circ} \mathrm{C}$ successively upregulated the expression of PD-L1 and IDO on the surface of tumor cells. They found that with time, the expression of IDO increased at $48 \mathrm{~h}$ after the heat treatment and then decreased at 72h. Whereas, the expression of PD-L1 have the highest expression at $72 \mathrm{~h}$. Moreover, the upregulated PD-L1 expression not only showed in tumor margins but also in distant tumors after hyperthermia (ablation temperature) (105-107). It remains to be elucidated that the upregulated coinhibitory molecules of PD-L1, PD-1, and Tim-3 are a cellular protective responses to avoid excessive immune activation or a byproducts from heat shock response when cells under damage. It should be noted that the upregulated coinhibitory molecules on tumor cells can also lead to impaired function of CD8 T cell. However, this upregulated immune checkpoint molecule can be neutralized by ICIs, and synergetic effect has been achieved for the combined hyperthermia and ICIs for tumor remission (see the following section). Thus, based on the foregoing reference that hyperthermia can either activate or enhance the immune response and upregulate PD-L1 in several kinds of tumors, we propose that treatment with hyperthermia creates a type I like tumor immune microenvironment with tumor infiltrating lymphocytes (TILs) and upregulates PD-L1 to work in complement with ICIs for cancer treatment (Figure 1).

\section{PRECLINICAL DATA COMBINING HYPERTHERMIA AND ICIs}

Discussed and researched for centuries, hyperthermia is seldom applied as a mainstream therapy or an adjuvant approach for cancer therapy. Clinical studies have researched the combination treatment of hyperthermia with cytokines and DCs; however, the results are conflicting. The reasons are mainly attributed to tumor tissue selection, antigen load in vitro and in vivo, and whether DCs could be recruited effectively. Despite the conflicting results of hyperthermia with traditional immune treatment and the constraint of antigen masking or shielding, thermoresistance, the bystander effect of HS-TEX and possible high expression of PD-L1 in HS-TEX, preclinical research of the combination regimens involving hyperthermia and ICIs has achieved optimistic results. However, hyperthermia is mainly restricted to nanoparticle-mediated hyperthermia and radiofrequency ablation.

Nanoparticle-mediated hyperthermia is a localized noninvasive treatment with controllable irradiation that has emerged as a new paradigm towards precise cancer therapy. Nanoparticle-mediated hyperthermia includes photothermal therapy and magnetic hyperthermia. Studies have found that the combination of ICIs (CTLA-4, PD-L1, IDO) and nanoparticle-mediated hyperthermia can promote antigen capture, enhance ICD effect, inhibit Treg cells' function, promote M1 macrophages' differentiation, recruit several folds of tumor-infiltrating lymphocytes, and achieve lasting memory for the inhibition of tumor growth in primary and distant sites 
(106-114). The synergetic role of heat and ICIs is further confirmed by results that enhanced tumor antigen-specific $\mathrm{T}$ cell responses and an increased Teff to Treg ratio in distant tumors with a combination of RFA and anti-PD-1 mAb administration (105). Despite the favorable results, several studies have shown limited results for complete tumor remission for ICIs with hyperthermia. Thus, triple combination strategies including ICIs with radio-/chemotherapy or TLR agonists have been studied, and they have also achieved favorable results with decreased tumor volume, increased metastatic dissemination, prevention of tumor rechallenge, and improved overall survival (115-126). A case report also found that hyperthermia and ipilimumab combined with IL-2 achieved complete clinical remission of stage IV triple-negative breast cancer with lung metastasis (127). Despite the favorable results, a preclinical study combining magnetic iron oxide nanoparticle hyperthermia and anti-PD-1 and anti-CTLA- 4 with a 4T1-luc cell mouse model also showed decreased tumor volume but increased metastatic dissemination and no improvement in overall survival (128). In fact, a study has shown that tumors quickly overcame immune responses by inhibiting the function of CD8 and CD4 T cells, driving a shift to a higher Treg/Teff ratio and upregulating PD-L1/PD-1 expression, which result suggested that tumor microenvironment after hyperthermia is variable and is favorable

TABLE 1 | Preclinical studies involving hyperthermia and immune checkpoint inhibitors.

\begin{tabular}{|c|c|c|c|c|}
\hline Hyperthermia & Immune checkpoint inhibitors & Temperature & Tumor (mouse model) & Reference \\
\hline CuS NPs-PEG-Mal-mediated PTT & Anti-PD-L1 mAb & $55^{\circ} \mathrm{C}$ & $4 \mathrm{~T} 1$ breast tumor & $(108)$ \\
\hline Mild photothermal & Anti-PD-L1 mAb & $45^{\circ} \mathrm{C}$ & $\begin{array}{l}\text { 4T1 breast tumor and B16- } \\
\text { F10 melanoma tumor }\end{array}$ & $(107)$ \\
\hline $\begin{array}{l}\text { CoFe2O4@MnFe2O4 nanoparticle-mediated } \\
\text { magnetic hyperthermia }\end{array}$ & Anti-PD-L1 mAb & $50^{\circ} \mathrm{C}$ & $4 \mathrm{~T} 1$ breast tumor & $(109)$ \\
\hline FVIOs-mediated magnetic hyperthermia & Anti-PD-L1 mAb & $43-44^{\circ} \mathrm{C}$ & $\begin{array}{l}\text { Orthotopic } 4 \mathrm{~T} 1 \text { breast } \\
\text { cancer }\end{array}$ & $(110)$ \\
\hline $\begin{array}{l}\text { Au nanoparticle-loaded membrane nanosheet } \\
\text { photothermal therapy }\end{array}$ & Anti-PD-L1 mAb & $64.4 \pm 1.4^{\circ} \mathrm{C}$ & B16-F10 melanoma-tumor & $(111)$ \\
\hline $\begin{array}{l}\text { GNPs-hPD-L1 siRNA-mediated } \\
\text { photothermal therapy }\end{array}$ & Nanoprism-assisted PD-L1 siRNA & $41.2^{\circ} \mathrm{C}$ & $\begin{array}{l}\text { HCC827 lung cancer cell } \\
\text { bearing tumor }\end{array}$ & $(112)$ \\
\hline $\begin{array}{l}\text { APP- and HAUNS-loaded PLGA nanoparticle } \\
\text { photothermal ablation }\end{array}$ & Sustained release anti-PD-1 peptide & $50-55^{\circ} \mathrm{C}$ & $\begin{array}{l}\text { 4T1 breast tumor and CT26 } \\
\text { tumor }\end{array}$ & $(113)$ \\
\hline $\begin{array}{l}\text { Au@Pt-LMDP conjugated photothermal- } \\
\text { immunotherapy }\end{array}$ & Release of a D-peptide antagonist of PD-L1 & $+20^{\circ} \mathrm{C}$ & $4 \mathrm{~T} 1$ breast tumor & $(114)$ \\
\hline NLG919/IR780 micelle-mediated PTT & IDO inhibitor & $54^{\circ} \mathrm{C}$ & MCF-7 breast cancer & $(106)$ \\
\hline \multicolumn{5}{|l|}{ Triple combination } \\
\hline $\begin{array}{l}\text { mPEG-Pep-IDOi/ICG NPs-mediated } \\
\text { phototherapy }\end{array}$ & Anti-PD-L1 mAb and nanoplatform of IDO inhibitor (IDOi) & $\begin{array}{l}\text { Maximum } \\
60^{\circ} \mathrm{C}\end{array}$ & B16-F10 melanoma tumor & $(115)$ \\
\hline $\begin{array}{l}\text { Magnetic iron oxide nanoparticle } \\
\text { hyperthermia }\end{array}$ & Anti-PD-1 mAb and anti-CTLA-4 mAb & $43^{\circ} \mathrm{C}$ & 4T1-luc breast cancer model & $(128)$ \\
\hline PEG-rGO-FA-IDOi-mediated PTT & Anti-PD-L1 mAb and IDOi & $53^{\circ} \mathrm{C}$ & CT26 colorectal cancer & $(116)$ \\
\hline $\begin{array}{l}\text { PDMN-JQ1 nanoplatform-mediated } \\
\text { photothermal therapy }\end{array}$ & $\begin{array}{l}\text { bromodomain and extra-terminal inhibitor JQ1 } \\
\text { downregulated the expression of PD-L1 and inhibited the } \\
\text { BRD4-C-MYC axis }\end{array}$ & $+21.7-20.3^{\circ} \mathrm{C}$ & 4T1 breast tumor & $(117)$ \\
\hline PDA-PEG-R848-CD nanoparticle PTT & Anti-PD-L1 mAb + PDA loaded with TLR7 agonist & $52.4^{\circ} \mathrm{C}$ & 4T1 breast tumor & $(118)$ \\
\hline Fe3O4-R837 SP-involved PTT & $\begin{array}{l}\text { Anti-PD-L1 mAb and nanoparticles loaded with Toll-like } \\
\text { receptor } 7 \text { agonist }\end{array}$ & $\begin{array}{l}\text { Ablation } \\
\text { temperature }\end{array}$ & $4 \mathrm{~T} 1$ breast tumor & $(119)$ \\
\hline $\begin{array}{l}\text { Iron nanoparticle-mediated magnetic } \\
\text { hyperthermia }\end{array}$ & Anti-CTLA-4 mAb and TLR7 agonist & $55^{\circ} \mathrm{C}$ & $\begin{array}{l}\text { CT26 mouse colon cancer } \\
\text { and murine B16 skin } \\
\text { melanoma }\end{array}$ & $(120)$ \\
\hline WO2.9-WSe2 nanoparticles I RT/PTT & Anti-PD-L1 mAb-based CBT + low radiation dose & $48^{\circ} \mathrm{C}$ & $4 \mathrm{~T} 1$ breast tumor & $(121)$ \\
\hline COF@ICG@OVA PTT/PDT therapy & Anti-PD-L1 mAb + PDT + PTT & $>63.5^{\circ} \mathrm{C}$ & H22 murine hepatoma & $(122)$ \\
\hline $\begin{array}{l}\text { Hyaluronic acid-shelled PPy/CPT } \\
\text { nanoparticles }\end{array}$ & Anti-PD-L1 mAb and camptothecin & $45-50^{\circ} \mathrm{C}$ & 4T1 Breast cancer & $(123)$ \\
\hline FA-CD@PP-CpG phototherapy & Anti-PD-L1 mAb+low dosage of loaded docetaxel & $44^{\circ} \mathrm{C}$ & 4T1 breast tumor & $(126)$ \\
\hline $\begin{array}{l}\text { Pd-Dox@TGMs NPs chemical-photothermal } \\
\text { therapy }\end{array}$ & Anti-PD-L1 mAb and doxorubicin & $51.2^{\circ} \mathrm{C}$ & CT26 colorectal cancer & $(124)$ \\
\hline $\begin{array}{l}\text { Cu-PPT + } 650+808 \mathrm{~nm} \text { laser photo/ } \\
\text { chemodynamic therapy }\end{array}$ & Glutathione peroxidase-mimicking and PD-L1 mAb & - & CT26 colorectal cancer & $(125)$ \\
\hline $\begin{array}{l}\text { Regional hyperthermia followed by systemic } \\
\text { fever-range hyperthermia induced by } \\
\text { interleukin-2 }\end{array}$ & Ipilimumab (case report) & $<42^{\circ} \mathrm{C}$ & $\begin{array}{l}\text { Stage IV triple-negative } \\
\text { breast cancer with lung } \\
\text { metastasis }\end{array}$ & $(127)$ \\
\hline \multicolumn{5}{|l|}{ Radiofrequency ablation } \\
\hline \multirow[t]{2}{*}{ Radiofrequency ablation } & Anti-PD-1 mAbs & $>45^{\circ} \mathrm{C}$ & CT26 mouse colon cancer & $(105)$ \\
\hline & Atezolizumab (case report) & $>45^{\circ} \mathrm{C}$ & $\begin{array}{l}\text { Stage IV non-small cell lung } \\
\text { cancer }\end{array}$ & $(129)$ \\
\hline
\end{tabular}


for anti-PD-1/PD-L1mAb treatment for only a narrow time window (105). Thus, compared to similar studies mentioned above, the reasons may partially be attributed to the unsynchronized treatment of hyperthermia and ICIs, for which other reasons should be explored to avoid further clinical failure. Detailed information on the combination therapies is shown in Table $\mathbf{1 .}$

\section{CONCLUSIONS AND FUTURE CHALLENGES}

Providing danger signals and reforming immune cells in the TME, hyperthermia is involved in multiple steps of regulating pathways in the cancer-immunity cycle; the immunomodulatory effect not only makes hyperthermia a treatment capable of defending against cancer but also makes the regimens of hyperthermia and ICIs a promising treatment for clinical use. Two of the major concerns are whether this combination is sufficient for the initiation and clearance of the tumor and that the combination would not drag the result in the opposite direction, i.e., the super-progression of the tumor due to immunotolerance. For the first concern, selective combination with the known treatment would be a way for solution. In fact, both radiotherapy and chemotherapy can directly kill tumor cells, whose cell debris can be recognized as a tumor in situ vaccine that can promote the effect of ant-PD-1/PD-L1 mAb. Moreover, hyperthermia is a potent radio-/chemo-sensitizer via a series of supplementary cytotoxic effect (130). Thus, it is expected for efficacy of the triple combination of anti-PD-1/ PD-L1 mAb, hyperthermia and radio/chemotherapy in clinics. Moreover, it also seems promising for PARPi, anti-angiogenesis treatments and other treatments to substitute radio/chemotherapy to combine with $\mathrm{PD}-1 / \mathrm{PD}-\mathrm{L} 1 \mathrm{mAb}$ and hyperthermia for the

\section{REFERENCES}

1. Wu T, Dai Y. Tumor microenvironment and therapeutic response. Cancer Lett (2017) 387:61-8. doi: 10.1016/j.canlet.2016.01.043

2. Chen DS, Mellman I. Oncology meets immunology: the cancer-immunity cycle. Immunity (2013) 39(1):1-10. doi: 10.1016/j.immuni.2013.07.012

3. Teng MW, Ngiow SF, Ribas A, Smyth MJ. Classifying Cancers Based on Tcell Infiltration and PD-L1. Cancer Res (2015) 75(11):2139-45. doi: 10.1158/ 0008-5472.CAN-15-0255

4. Osipov A, Saung MT, Zheng L, Murphy AG. Small molecule immunomodulation: the tumor microenvironment and overcoming immune escape. J Immunother Cancer (2019) 7(1):224. doi: 10.1186/s40425-019-0667-0

5. Wang Y, Deng W, Li N, Neri S, Sharma A, Jiang W, et al. Combining Immunotherapy and Radiotherapy for Cancer Treatment: Current Challenges and Future Directions. Front Pharmacol (2018) 9:185. doi: 10.3389/fphar.2018.00185

6. Fukumura D, Kloepper J, Amoozgar Z, Duda DG, Jain RK. Enhancing cancer immunotherapy using antiangiogenics: opportunities and challenges. Nat Rev Clin Oncol (2018) 15(5):325-40. doi: 10.1038/nrclinonc.2018.29

7. Repasky EA, Evans SS, Dewhirst MW. Temperature matters! And why it should matter to tumor immunologists. Cancer Immunol Res (2013) 1 (4):210-6. doi: 10.1158/2326-6066.cir-13-0118

8. Germano G, Lamba S, Rospo G, Barault L, Magri A, Maione F, et al. Inactivation of DNA repair triggers neoantigen generation and impairs tumour growth. Nature (2017) 552(7683):116-20. doi: 10.1038/nature24673 treatment of tumors with low mutation, fewer neoantigens or disorganized tumor vessels. Thus, rational different combination therapies are promising for the eradication of tumors (131). For the second question, the authors believe that the patients should also be explored and selected for the combination, which point is also important for the first concern. Studies have found that certain gene mutations, such as KRAS, are more sensitive to hyperthermia as they exhibit sustained ERK signaling hyperactivation and increased Wingless/Integrated (WNT)/beta-catenin signalling (132). Moreover, using a bioinformatic approach, a series of molecules have been identified as determinants of resistance/sensitivity to thermotherapy (49). The results of the two studies offer ways for accurate selection when treated with hyperthermia. Last but not least, thermoequipment and procedures should be normalized with schedules based on the model system, the magnitude, the duration of the thermal stress, and the time of recovery after heat exposure (133). However, radiofrequency and local hyperthermia are the most commonly used hyperthermia regimens in clinical practice; they exploit ablation and mild temperature for treatment directly instead of the help of particle media. How they can be properly used with ICIs and whether they can achieve equally promising results remain to be elucidated.

\section{AUTHOR CONTRIBUTIONS}

ZL performed the manuscript preparation and drafted the manuscript. JD helped draft the manuscript. JS revised the manuscript and approved the final version. YM contributed to the conception and design of the current study, revised the manuscript, and approved the final version. All authors contributed to the article and approved the submitted version.

9. Schumacher TN, Scheper W, Kvistborg P. Cancer Neoantigens. Annu Rev Immunol (2019) 37:173-200. doi: 10.1146/annurev-immunol-042617053402

10. Mantso T, Goussetis G, Franco R, Botaitis S, Pappa A, Panayiotidis M. Effects of hyperthermia as a mitigation strategy in DNA damage-based cancer therapies. Semin Cancer Biol (2016) 37-38:96-105. doi: 10.1016/ j.semcancer.2016.03.004

11. Oei AL, Vriend LEM, Krawczyk PM, Horsman MR, Franken NAP, Crezee J. Targeting therapy-resistant cancer stem cells by hyperthermia. Int J Hyperthermia (2017) 33(4):419-27. doi: 10.1080/02656736.2017.1279757

12. Bewicke-Copley F, Mulcahy LA, Jacobs LA, Samuel P, Akbar N, Pink RC, et al. Extracellular vesicles released following heat stress induce bystander effect in unstressed populations. J Extracell Vesicles (2017) 6(1):1340746. doi: 10.1080/20013078.2017.1340746

13. Hurwitz M, Stauffer P. Hyperthermia, radiation and chemotherapy: the role of heat in multidisciplinary cancer care. Semin Oncol (2014) 41(6):714-29. doi: 10.1053/j.seminoncol.2014.09.014

14. Radogna F, Diederich M. Stress-induced cellular responses in immunogenic cell death: Implications for cancer immunotherapy. Biochem Pharmacol (2018) 153:12-23. doi: 10.1016/j.bcp.2018.02.006

15. Krysko DV, Garg AD, Kaczmarek A, Krysko O, Agostinis P, Vandenabeele P. Immunogenic cell death and DAMPs in cancer therapy. Nat Rev Cancer (2012) 12(12):860-75. doi: 10.1038/nrc3380

16. Garg AD, Krysko DV, Verfaillie T, Kaczmarek A, Ferreira GB, Marysael T, et al. A novel pathway combining calreticulin exposure and ATP secretion in 
immunogenic cancer cell death. EMBO J (2012) 31(5):1062-79. doi: 10.1038/ emboj.2011.497

17. Panaretakis T, Kepp O, Brockmeier U, Tesniere A, Bjorklund AC, Chapman DC, et al. Mechanisms of pre-apoptotic calreticulin exposure in immunogenic cell death. EMBO J (2009) 28(5):578-90. doi: 10.1038/emboj.2009.1

18. Nagata S, Tanaka M. Programmed cell death and the immune system. Nat Rev Immunol (2017) 17(5):333-40. doi: 10.1038/nri.2016.153

19. Inoue $\mathrm{H}$, Tani K. Multimodal immunogenic cancer cell death as a consequence of anticancer cytotoxic treatments. Cell Death Differ (2014) 21(1):39-49. doi: 10.1038/cdd.2013.84

20. Kepp O, Zitvogel L, Kroemer G. Clinical evidence that immunogenic cell death sensitizes to PD-1/PD-L1 blockade. Oncoimmunology (2019) 8(10): e1637188. doi: 10.1080/2162402x.2019.1637188

21. González FE, Gleisner A, Falcón-Beas F, Osorio F, López MN, SalazarOnfray F. Tumor cell lysates as immunogenic sources for cancer vaccine design. Hum Vaccin Immunother (2014) 10(11):3261-9. doi: 10.4161/ 21645515.2014.982996

22. Melief CJ. Mini-review: Regulation of cytotoxic T lymphocyte responses by dendritic cells: peaceful coexistence of cross-priming and direct priming? Eur J Immunol (2003) 33(10):2645-54. doi: 10.1002/eji.200324341

23. Diederich CJ. Thermal ablation and high-temperature thermal therapy: overview of technology and clinical implementation. Int J Hyperthermia (2005) 21(8):745-53. doi: 10.1080/02656730500271692

24. Kono H, Rock KL. How dying cells alert the immune system to danger. Nat Rev Immunol (2008) 8(4):279-89. doi: 10.1038/nri2215

25. de Andrade Mello P, Bian S, Savio LEB, Zhang H, Zhang J, Junger W, et al. Hyperthermia and associated changes in membrane fluidity potentiate P2X7 activation to promote tumor cell death. Oncotarget (2017) 8(40):67254-68. doi: 10.18632 /oncotarget. 18595

26. Homma T, Fujii J. Heat stress promotes the down-regulation of IRE1 $\alpha$ in cells: An atypical modulation of the UPR pathway. Exp Cell Res (2016) 349 (1):128-38. doi: 10.1016/j.yexcr.2016.10.006

27. Pallepati P, Averill-Bates D. Mild thermotolerance induced at 40 degrees $C$ increases antioxidants and protects HeLa cells against mitochondrial apoptosis induced by hydrogen peroxide: Role of p53. Arch Biochem Biophys (2010) 495(2):97-111. doi: 10.1016/j.abb.2009.12.014

28. Bezu L, Sauvat A, Humeau J, Gomes-da-Silva LC, Iribarren K, Forveille S, et al. eIF2 $\alpha$ phosphorylation is pathognomonic for immunogenic cell death. Cell Death Differ (2018) 25(8):1375-93. doi: 10.1038/s41418-017-0044-9

29. Kepp O, Semeraro M, Bravo-San Pedro JM, Bloy N, Buqué A, Huang X, et al. eIF2 $\alpha$ phosphorylation as a biomarker of immunogenic cell death. Semin Cancer Biol (2015) 33:86-92. doi: 10.1016/j.semcancer.2015.02.004

30. Bettaieb A, Averill-Bates DA. Thermotolerance induced at a mild temperature of $40^{\circ} \mathrm{C}$ alleviates heat shock-induced ER stress and apoptosis in HeLa cells. Biochim Biophys Acta (2015) 1853(1):52-62. doi: 10.1016/j.bbamcr.2014.09.016

31. Mantso T, Vasileiadis S, Anestopoulos I, Voulgaridou GP, Lampri E, Botaitis S, et al. Hyperthermia induces therapeutic effectiveness and potentiates adjuvant therapy with non-targeted and targeted drugs in an in vitro model of human malignant melanoma. Sci Rep (2018) 8(1):10724. doi: 10.1038/s41598-01829018-0

32. Wang Q, Ju X, Wang J, Fan Y, Ren M, Zhang H. Immunogenic cell death in anticancer chemotherapy and its impact on clinical studies. Cancer Lett (2018) 438:17-23. doi: 10.1016/j.canlet.2018.08.028

33. Aguilera R, Saffie C, Tittarelli A, González FE, Ramírez M, Reyes D, et al. Heat-shock induction of tumor-derived danger signals mediates rapid monocyte differentiation into clinically effective dendritic cells. Clin Cancer Res (2011) 17(8):2474-83. doi: 10.1158/1078-0432.ccr-10-2384

34. Shi H, Cao T, Connolly JE, Monnet L, Bennett L, Chapel S, et al. Hyperthermia enhances CTL cross-priming. J Immunol (2006) 176 (4):2134-41. doi: 10.4049/jimmunol.176.4.2134

35. Meggyeshazi N, Andocs G, Balogh L, Balla P, Kiszner G, Teleki I, et al. DNA fragmentation and caspase-independent programmed cell death by modulated electrohyperthermia. Strahlenther Onkol (2014) 190(9):815-22. doi: 10.1007/s00066-014-0617-1

36. Vancsik T, Kovago C, Kiss E, Papp E, Forika G, Benyo Z, et al. Modulated electro-hyperthermia induced loco-regional and systemic tumor destruction in colorectal cancer allografts. J Cancer (2018) 9(1):41-53. doi: 10.7150/ jca. 21520
37. Hou CH, Lin FL, Hou SM, Liu JF. Hyperthermia induces apoptosis through endoplasmic reticulum and reactive oxygen species in human osteosarcoma cells. Int J Mol Sci (2014) 15(10):17380-95. doi: 10.3390/ijms151017380

38. Adkins I, Fucikova J, Garg AD, Agostinis P, Spisek R. Physical modalities inducing immunogenic tumor cell death for cancer immunotherapy. Oncoimmunology (2014) 3(12):e968434. doi: 10.4161/21624011.2014.968434

39. O'Brien MA, Power DG, Clover AJ, Bird B, Soden DM, Forde PF. Local tumour ablative therapies: opportunities for maximising immune engagement and activation. Biochim Biophys Acta (2014) 1846(2):510-23. doi: 10.1016/j.bbcan.2014.09.005

40. González FE, Chernobrovkin A, Pereda C, García-Salum T, Tittarelli A, López MN, et al. Proteomic Identification of Heat Shock-Induced Danger Signals in a Melanoma Cell Lysate Used in Dendritic Cell-Based Cancer Immunotherapy. J Immunol Res (2018) 2018:3982942. doi: 10.1155/2018/3982942

41. Chen T, Guo J, Han C, Yang M, Cao X. Heat shock protein 70, released from heat-stressed tumor cells, initiates antitumor immunity by inducing tumor cell chemokine production and activating dendritic cells via TLR4 pathway. J Immunol (2009) 182(3):1449-59. doi: 10.4049/jimmunol.182.3.1449

42. Calderwood SK. Heat shock proteins and cancer: intracellular chaperones or extracellular signalling ligands? Philos Trans R Soc Lond B Biol Sci (2018) 373 (1738). doi: 10.1098/rstb.2016.0524

43. Tomasovic SP, Simonette RA, Wolf DA, Kelley KL, Updyke TV. Co-isolation of heat stress and cytoskeletal proteins with plasma membrane proteins. Int $J$ Hyperthermia (1989) 5(2):173-90. doi: 10.3109/02656738909140446

44. Shevtsov M, Huile G, Multhoff G. Membrane heat shock protein 70: a theranostic target for cancer therapy. Philos Trans R Soc Lond B Biol Sci (2018) 373(1738). doi: 10.1098/rstb.2016.0526

45. Zhu J, Zhang Y, Zhang A, He K, Liu P, Xu LX. Cryo-thermal therapy elicits potent anti-tumor immunity by inducing extracellular Hsp70-dependent MDSC differentiation. Sci Rep (2016) 6:27136. doi: 10.1038/srep27136

46. Schildkopf P, Frey B, Ott OJ, Rubner Y, Multhoff G, Sauer R, et al. Radiation combined with hyperthermia induces HSP70-dependent maturation of dendritic cells and release of pro-inflammatory cytokines by dendritic cells and macrophages. Radiother Oncol (2011) 101(1):109-15. doi: 10.1016/ j.radonc.2011.05.056

47. Ito A, Fujioka M, Tanaka K, Kobayashi T, Honda H. Screening of cytokines to enhance vaccine effects of heat shock protein 70-rich tumor cell lysate. J Biosci Bioeng (2005) 100(1):36-42. doi: 10.1263/jbb.100.36

48. Lin FC, Hsu CH, Lin YY. Nano-therapeutic cancer immunotherapy using hyperthermia-induced heat shock proteins: insights from mathematical modeling. Int J Nanomedicine (2018) 13:3529-39. doi: 10.2147/ijn.s166000

49. Duzgun MB, Theofilatos K, Georgakilas AG, Pavlopoulou A. A Bioinformatic Approach for the Identification of Molecular Determinants of Resistance/Sensitivity to Cancer Thermotherapy. Oxid Med Cell Longev (2019) 2019:4606219. doi: 10.1155/2019/4606219

50. Ostberg JR, Repasky EA. Emerging evidence indicates that physiologically relevant thermal stress regulates dendritic cell function. Cancer Immunol Immunother (2006) 55(3):292-8. doi: 10.1007/s00262-005-0689-y

51. Knippertz I, Stein MF, Dorrie J, Schaft N, Muller I, Deinzer A, et al. Mild hyperthermia enhances human monocyte-derived dendritic cell functions and offers potential for applications in vaccination strategies. Int $J$ Hyperthermia (2011) 27(6):591-603. doi: 10.3109/02656736.2011.589234

52. Feng M, Jiang W, Kim BYS, Zhang CC, Fu YX, Weissman IL. Phagocytosis checkpoints as new targets for cancer immunotherapy. Nat Rev Cancer (2019) 19(10):568-86. doi: 10.1038/s41568-019-0183-z

53. Adkins I, Sadilkova L, Hradilova N, Tomala J, Kovar M, Spisek R. Severe, but not mild heat-shock treatment induces immunogenic cell death in cancer cells. Oncoimmunology (2017) 6(5):el311433. doi: 10.1080/2162402x.2017.1311433

54. Garg AD, Romano E, Rufo N, Agostinis P. Immunogenic versus tolerogenic phagocytosis during anticancer therapy: mechanisms and clinical translation. Cell Death Differ (2016) 23(6):938-51. doi: 10.1038/cdd.2016.5

55. Dudek AM, Martin S, Garg AD, Agostinis P. Immature, Semi-Mature, and Fully Mature Dendritic Cells: Toward a DC-Cancer Cells Interface That Augments Anticancer Immunity. Front Immunol (2013) 4:438. doi: 10.3389/ fimmu.2013.00438

56. Kubes J, Svoboda J, Rosina J, Starec M, Fiserova A. Immunological response in the mouse melanoma model after local hyperthermia. Physiol Res (2008) 57(3):459-65. 
57. Liu P, Jia S, Lou Y, He K, Xu LX. Cryo-thermal therapy inducing MI macrophage polarization created CXCL10 and IL-6-rich pro-inflammatory environment for $\mathrm{CD} 4(+) \mathrm{T}$ cell-mediated anti-tumor immunity. Int $J$ Hyperthermia (2019) 36(1):408-20. doi: 10.1080/02656736.2019.1579373

58. He K, Jia S, Lou Y, Liu P, Xu LX. Cryo-thermal therapy induces macrophage polarization for durable anti-tumor immunity. Cell Death Dis (2019) 10 (3):216. doi: 10.1038/s41419-019-1459-7

59. Sabado RL, Balan S, Bhardwaj N. Dendritic cell-based immunotherapy. Cell Res (2017) 27(1):74-95. doi: 10.1038/cr.2016.157

60. Hargadon KM. Strategies to Improve the Efficacy of Dendritic Cell-Based Immunotherapy for Melanoma. Front Immunol (2017) 8:1594. doi: 10.3389/ fimmu.2017.01594

61. Matsumoto K, Yamamoto N, Hagiwara S, Saito M, Furue H, Shigetomi T, et al. Optimization of hyperthermia and dendritic cell immunotherapy for squamous cell carcinoma. Oncol Rep (2011) 25(6):1525-32. doi: 10.3892/ or.2011.1232

62. Menga M, Trotta R, Scrima R, Pacelli C, Silvestri V, Piccoli C, et al. Febrile temperature reprograms by redox-mediated signaling the mitochondrial metabolic phenotype in monocyte-derived dendritic cells. Biochim Biophys Acta Mol Basis Dis (2018) 1864(3):685-99. doi: 10.1016/j.bbadis.2017.12.010

63. Liso A, Capitanio N, Gerli R, Conese M. From fever to immunity: A new role for IGFBP-6? J Cell Mol Med (2018) 22(10):4588-96. doi: 10.1111/jcmm.13738

64. Zhou L, Chong MM, Littman DR. Plasticity of CD4+ T cell lineage differentiation. Immunity (2009) 30(5):646-55. doi: 10.1016/j.immuni.2009.05.001

65. Wan YY. Multi-tasking of helper T cells. Immunology (2010) 130(2):166-71. doi: 10.1111/j.1365-2567.2010.03289.x

66. Kim HJ, Cantor H. CD4 T-cell subsets and tumor immunity: the helpful and the not-so-helpful. Cancer Immunol Res (2014) 2(2):91-8. doi: 10.1158/ 2326-6066.CIR-13-0216

67. Fridman WH, Pages F, Sautes-Fridman C, Galon J. The immune contexture in human tumours: impact on clinical outcome. Nat Rev Cancer (2012) 12 (4):298-306. doi: 10.1038/nrc3245

68. Najafi S, Mirshafiey A. The role of $\mathrm{T}$ helper 17 and regulatory $\mathrm{T}$ cells in tumor microenvironment. Immunopharmacol Immunotoxicol (2019) 41 (1):16-24. doi: 10.1080/08923973.2019.1566925

69. Zuazo M, Arasanz H, Bocanegra A, Chocarro L, Vera R, Escors D, et al. Systemic CD4 immunity: A powerful clinical biomarker for PD-L1/PD-1 immunotherapy. EMBO Mol Med (2020) 12(9):e12706. doi: 10.15252/ emmm.202012706

70. Zuazo M, Arasanz H, Fernández-Hinojal G, García-Granda MJ, Gato M, Bocanegra A, et al. Functional systemic CD4 immunity is required for clinical responses to PD-L1/PD-1 blockade therapy. EMBO Mol Med (2019) 11(7):e10293. doi: 10.15252/emmm.201910293

71. Liu K, He K, Xue T, Liu P, Xu LX. The cryo-thermal therapy-induced IL-6rich acute pro-inflammatory response promoted DCs phenotypic maturation as the prerequisite to $\mathrm{CD} 4(+) \mathrm{T}$ cell differentiation. Int $J$ Hyperthermia (2018) 34(3):261-72. doi: 10.1080/02656736.2017.1332394

72. Du G, Liu Y, Li J, Liu W, Wang Y, Li H. Hypothermic microenvironment plays a key role in tumor immune subversion. Int Immunopharmacol (2013) 17(2):245-53. doi: 10.1016/j.intimp.2013.06.018

73. Duan XH, Li H, Han XW, Ren JZ, Li FY, Ju SG, et al. Upregulation of IL-6 is involved in moderate hyperthermia induced proliferation and invasion of hepatocellular carcinoma cells. Eur J Pharmacol (2018) 833:230-6. doi: 10.1016/j.ejphar.2018.06.014

74. Hong M, Jiang Z, Zhou YF. Effects of thermotherapy on Th1/Th2 cells in esophageal cancer patients treated with radiotherapy. Asian Pac J Cancer Prev (2014) 15(5):2359-62. doi: 10.7314/apjcp.2014.15.5.2359

75. Cho JA, Lee YS, Kim SH, Ko JK, Kim CW. MHC independent anti-tumor immune responses induced by Hsp70-enriched exosomes generate tumor regression in murine models. Cancer Lett (2009) 275(2):256-65. doi: 10.1016/j.canlet.2008.10.021

76. Guo D, Chen Y, Wang S, Yu L, Shen Y, Zhong H, et al. Exosomes from heatstressed tumour cells inhibit tumour growth by converting regulatory $\mathrm{T}$ cells to Th17 cells via IL-6. Immunology (2018) 154(1):132-43. doi: 10.1111/imm.12874

77. Newton JM, Flores-Arredondo JH, Suki S, Ware MJ, Krzykawska-Serda M, Agha M, et al. Non-Invasive Radiofrequency Field Treatment of 4T1 Breast Tumors Induces T-cell Dependent Inflammatory Response. Sci Rep (2018) 8 (1):3474. doi: 10.1038/s41598-018-21719-w
78. Chen Q, Fisher DT, Kucinska SA, Wang WC, Evans SS. Dynamic control of lymphocyte trafficking by fever-range thermal stress. Cancer Immunol Immunother (2006) 55(3):299-311. doi: 10.1007/s00262-005-0022-9

79. Chen Q, Appenheimer MM, Muhitch JB, Fisher DT, Clancy KA, Miecznikowski JC, et al. Thermal facilitation of lymphocyte trafficking involves temporal induction of intravascular ICAM-1. Microcirculation (2009) 16(2):143-58. doi: 10.1080/10739680802353850

81. Evans SS, Wang WC, Bain MD, Burd R, Ostberg JR, Repasky EA. Feverrange hyperthermia dynamically regulates lymphocyte delivery to high endothelial venules. Blood (2001) 97(9):2727-33. doi: 10.1182/ blood.v97.9.2727

80. Chen Q, Fisher DT, Clancy KA, Gauguet JM, Wang WC, Unger E, et al. Fever-range thermal stress promotes lymphocyte trafficking across high endothelial venules via an interleukin 6 trans-signaling mechanism. Nat Immunol (2006) 7(12):1299-308. doi: 10.1038/ni1406

82. Xue T, Liu P, Zhou Y, Liu K, Yang L, Moritz RL, et al. Interleukin-6 Induced "Acute" Phenotypic Microenvironment Promotes Th1 Anti-Tumor Immunity in Cryo-Thermal Therapy Revealed By Shotgun and Parallel Reaction Monitoring Proteomics. Theranostics (2016) 6(6):773-94. doi: $10.7150 /$ thno. 14394

83. Fisher DT, Chen Q, Skitzki JJ, Muhitch JB, Zhou L, Appenheimer MM, et al. IL-6 trans-signaling licenses mouse and human tumor microvascular gateways for trafficking of cytotoxic T cells. J Clin Invest (2011) 121 (10):3846-59. doi: 10.1172/JCI44952

84. Kushida S, Ohmae H, Kamma H, Totsuka R, Matsumura M, Takeuchi A, et al. Artificial cytokine storm combined with hyperthermia induces significant anti-tumor effect in mice inoculated with lewis lung carcinoma and B16 melanoma cells. Int J Hyperthermia (2006) 22(8):699-712. doi: $10.1080 / 02656730601088508$

85. O'Neill CP, Gilligan KE, Dwyer RM. Role of Extracellular Vesicles (EVs) in Cell Stress Response and Resistance to Cancer Therapy. Cancers (Basel) (2019) 11(2). doi: 10.3390/cancers11020136

86. Yang Y, Chen Y, Zhang F, Zhao Q, Zhong H. Increased anti-tumour activity by exosomes derived from doxorubicin-treated tumour cells via heat stress. Int $J$ Hyperthermia (2015) 31(5):498-506. doi: 10.3109/02656736.2015.1036384

87. Chen T, Guo J, Yang M, Zhu X, Cao X. Chemokine-containing exosomes are released from heat-stressed tumor cells via lipid raft-dependent pathway and act as efficient tumor vaccine. J Immunol (2011) 186(4):2219-28. doi: 10.4049/jimmunol.1002991

88. Zhong H, Yang Y, Ma S, Xiu F, Cai Z, Zhao H, et al. Induction of a tumourspecific CTL response by exosomes isolated from heat-treated malignant ascites of gastric cancer patients. Int J Hyperthermia (2011) 27(6):604-11. doi: $10.3109 / 02656736.2011 .564598$

89. Dai S, Wan T, Wang B, Zhou X, Xiu F, Chen T, et al. More efficient induction of HLA-A*0201-restricted and carcinoembryonic antigen (CEA)specific CTL response by immunization with exosomes prepared from heatstressed CEA-positive tumor cells. Clin Cancer Res (2005) 11(20):7554-63. doi: 10.1158/1078-0432.CCR-05-0810

90. Chen W, Wang J, Shao C, Liu S, Yu Y, Wang Q, et al. Efficient induction of antitumor $\mathrm{T}$ cell immunity by exosomes derived from heat-shocked lymphoma cells. Eur J Immunol (2006) 36(6):1598-607. doi: 10.1002/eji.200535501

91. Gastpar R, Gehrmann M, Bausero MA, Asea A, Gross C, Schroeder JA, et al. Heat shock protein 70 surface-positive tumor exosomes stimulate migratory and cytolytic activity of natural killer cells. Cancer Res (2005) 65(12):523847. doi: 10.1158/0008-5472.CAN-04-3804

92. Poggio M, Hu T, Pai CC, Chu B, Belair CD, Chang A, et al. Suppression of Exosomal PD-L1 Induces Systemic Anti-tumor Immunity and Memory. Cell (2019) 177(2):414-427 e413. doi: 10.1016/j.cell.2019.02.016

93. Verdeil G, Fuertes Marraco SA, Murray T, Speiser DE. From T cell "exhaustion" to anti-cancer immunity. Biochim Biophys Acta (2016) 1865 (1):49-57. doi: 10.1016/j.bbcan.2015.06.007

94. Frey AB. Suppression of $\mathrm{T}$ cell responses in the tumor microenvironment. Vaccine (2015) 33(51):7393-400. doi: 10.1016/j.vaccine.2015.08.096

95. Baitsch L, Fuertes-Marraco SA, Legat A, Meyer C, Speiser DE. The three main stumbling blocks for anticancer T cells. Trends Immunol (2012) 33 (7):364-72. doi: 10.1016/j.it.2012.02.006

96. Davoodzadeh Gholami M, Kardar GA, Saeedi Y, Heydari S, Garssen J, Falak R. Exhaustion of $\mathrm{T}$ lymphocytes in the tumor microenvironment: 
Significance and effective mechanisms. Cell Immunol (2017) 322:1-14. doi: 10.1016/j.cellimm.2017.10.002

97. Olofsson R, Lindberg E, Karlsson-Parra A, Lindnér P, Mattsson J, Andersson B. Melan-A specific CD8+ T lymphocytes after hyperthermic isolated limb perfusion: a pilot study in patients with in-transit metastases of malignant melanoma. Int $J$ Hyperthermia (2013) 29(3):234-8. doi: 10.3109/02656736.2013.782428

98. Gleisner MA, Pereda C, Tittarelli A, Navarrete M, Fuentes C, Avalos I, et al. A heat-shocked melanoma cell lysate vaccine enhances tumor infiltration by prototypic effector T cells inhibiting tumor growth. J Immunother Cancer (2020) 8(2). doi: 10.1136/jitc-2020-000999

99. Mace TA, Zhong L, Kilpatrick C, Zynda E, Lee CT, Capitano M, et al. Differentiation of CD8+ T cells into effector cells is enhanced by physiological range hyperthermia. J Leukoc Biol (2011) 90(5):951-62. doi: $10.1189 / \mathrm{jlb} .0511229$

100. Mace TA, Zhong L, Kokolus KM, Repasky EA. Effector CD8+ T cell IFNgamma production and cytotoxicity are enhanced by mild hyperthermia. Int J Hyperthermia (2012) 28(1):9-18. doi: 10.3109/02656736.2011.616182

101. Cippitelli M, Fionda C, Di Bona D, Piccoli M, Frati L, Santoni A. Hyperthermia enhances CD95-ligand gene expression in T lymphocytes. J Immunol (2005) 174(1):223-32. doi: 10.4049/jimmunol.174.1.223

102. Jiang Y, Li Y, Zhu B. T-cell exhaustion in the tumor microenvironment. Cell Death Dis (2015) 6:e1792. doi: 10.1038/cddis.2015.162

103. He K, Liu P, Xu LX. The cryo-thermal therapy eradicated melanoma in mice by eliciting CD4(+) T-cell-mediated antitumor memory immune response. Cell Death Dis (2017) 8(3):e2703. doi: 10.1038/cddis.2017.125

104. Atanackovic D, Pollok K, Faltz C, Boeters I, Jung R, Nierhaus A, et al. Patients with solid tumors treated with high-temperature whole body hyperthermia show a redistribution of naive/memory T-cell subtypes. Am J Physiol Regul Integr Comp Physiol (2006) 290(3):R585-594. doi: 10.1152/ ajpregu.00014.2005

105. Shi L, Chen L, Wu C, Zhu Y, Xu B, Zheng X, et al. PD-1 Blockade Boosts Radiofrequency Ablation-Elicited Adaptive Immune Responses against Tumor. Clin Cancer Res (2016) 22(5):1173-84. doi: 10.1158/1078-0432.ccr-15-1352

106. Peng J, Xiao Y, Li W, Yang Q, Tan L, Jia Y, et al. Photosensitizer Micelles Together with IDO Inhibitor Enhance Cancer Photothermal Therapy and Immunotherapy. Adv Sci (Weinh) (2018) 5(5):1700891. doi: 10.1002/ advs.201700891

107. Huang L, Li Y, Du Y, Zhang Y, Wang X, Ding Y, et al. Mild photothermal therapy potentiates anti-PD-L1 treatment for immunologically cold tumors via an all-in-one and all-in-control strategy. Nat Commun (2019) 10(1):4871. doi: 10.1038/s41467-019-12771-9

108. Wang R, He Z, Cai P, Zhao Y, Gao L, Yang W, et al. Surface-Functionalized Modified Copper Sulfide Nanoparticles Enhance Checkpoint Blockade Tumor Immunotherapy by Photothermal Therapy and Antigen Capturing. ACS Appl Mater Interfaces (2019) 11(15):13964-72. doi: 10.1021/acsami.9b01107

109. Pan J, Hu P, Guo Y, Hao J, Ni D, Xu Y, et al. Combined Magnetic Hyperthermia and Immune Therapy for Primary and Metastatic Tumor Treatments. ACS Nano (2020) 14(1):1033-44. doi: 10.1021/acsnano.9b08550

110. Liu X, Zheng J, Sun W, Zhao X, Li Y, Gong N, et al. Ferrimagnetic Vortex Nanoring-Mediated Mild Magnetic Hyperthermia Imparts Potent Immunological Effect for Treating Cancer Metastasis. ACS Nano (2019) 13 (8):8811-25. doi: 10.1021/acsnano.9b01979

111. Li X, Liu J, Zhang W, Wu Y, Li J, Foda MF, et al. Biogenic Hybrid Nanosheets Activated Photothermal Therapy and Promoted Anti-PD-L1 Efficacy for Synergetic Antitumor Strategy. ACS Appl Mater Interfaces (2020) 12 (26):29122-32. doi: 10.1021/acsami.0c09111

112. Liu B, Cao W, Qiao G, Yao S, Pan S, Wang L, et al. Effects of gold nanoprismassisted human PD-L1 siRNA on both gene down-regulation and photothermal therapy on lung cancer. Acta Biomater (2019) 99:307-19. doi: 10.1016/j.actbio.2019.08.046

113. Luo L, Yang J, Zhu C, Jiang M, Guo X, Li W, et al. Sustained release of antiPD-1 peptide for perdurable immunotherapy together with photothermal ablation against primary and distant tumors. J Control Release (2018) 278:87-99. doi: 10.1016/j.jconrel.2018.04.002

114. Yang Q, Peng J, Shi K, Xiao Y, Liu Q, Han R, et al. Rationally designed peptide-conjugated gold/platinum nanosystem with active tumor-targeting for enhancing tumor photothermal-immunotherapy. J Control Release (2019) 308:29-43. doi: 10.1016/j.jconrel.2019.06.031
115. Liu Y, Lu Y, Zhu X, Li C, Yan M, Pan J, et al. Tumor microenvironmentresponsive prodrug nanoplatform via co-self-assembly of photothermal agent and IDO inhibitor for enhanced tumor penetration and cancer immunotherapy. Biomaterials (2020) 242:119933. doi: 10.1016/ j.biomaterials.2020.119933

116. Yan M, Liu Y, Zhu X, Wang X, Liu L, Sun H, et al. Nanoscale Reduced Graphene Oxide-Mediated Photothermal Therapy Together with IDO Inhibition and PD-L1 Blockade Synergistically Promote Antitumor Immunity. ACS Appl Mater Interfaces (2019) 11(2):1876-85. doi: 10.1021/ acsami.8b18751

117. Tian Y, Wang X, Zhao S, Liao X, Younis MR, Wang S, et al. JQ1-Loaded Polydopamine Nanoplatform Inhibits c-MYC/Programmed Cell Death Ligand 1 to Enhance Photothermal Therapy for Triple-Negative Breast Cancer. ACS Appl Mater Interfaces (2019) 11(50):46626-36. doi: 10.1021/ acsami.9b18730

118. Lu Q, Qi S, Li P, Yang L, Yang S, Wang Y, et al. Photothermally activatable PDA immune nanomedicine combined with PD-L1 checkpoint blockade for antimetastatic cancer photoimmunotherapy. J Mater Chem B (2019) 7 (15):2499-511. doi: 10.1039/c9tb00089e

119. Ge R, Liu C, Zhang X, Wang W, Li B, Liu J, et al. Photothermal-Activatable Fe3O4 Superparticle Nanodrug Carriers with PD-L1 Immune Checkpoint Blockade for Anti-metastatic Cancer Immunotherapy. ACS Appl Mater Interfaces (2018) 10(24):20342-55. doi: 10.1021/acsami.8b05876

120. Chao Y, Chen G, Liang C, Xu J, Dong Z, Han X, et al. Iron Nanoparticles for Low-Power Local Magnetic Hyperthermia in Combination with Immune Checkpoint Blockade for Systemic Antitumor Therapy. Nano Lett (2019) 19 (7):4287-96. doi: 10.1021/acs.nanolett.9b00579

121. Dong X, Cheng R, Zhu S, Liu H, Zhou R, Zhang C, et al. A Heterojunction Structured WO(2.9)-WSe(2) Nanoradiosensitizer Increases Local Tumor Ablation and Checkpoint Blockade Immunotherapy upon Low Radiation Dose. ACS Nano (2020) 14(5):5400-16. doi: 10.1021/acsnano.9b08962

122. Zhou Y, Liu S, Hu C, Cai L, Pang M. A covalent organic framework as a nanocarrier for synergistic phototherapy and immunotherapy. J Mater Chem B (2020) 8(25):5451-9. doi: 10.1039/d0tb00679c

123. Sun W, Du Y, Liang X, Yu C, Fang J, Lu W, et al. Synergistic triplecombination therapy with hyaluronic acid-shelled PPy/CPT nanoparticles results in tumor regression and prevents tumor recurrence and metastasis in 4T1 breast cancer. Biomaterials (2019) 217:119264. doi: 10.1016/ j.biomaterials.2019.119264

124. Wen Y, Chen X, Zhu X, Gong Y, Yuan G, Qin X, et al. PhotothermalChemotherapy Integrated Nanoparticles with Tumor Microenvironment Response Enhanced the Induction of Immunogenic Cell Death for Colorectal Cancer Efficient Treatment. ACS Appl Mater Interfaces (2019) 11(46):43393-408. doi: 10.1021/acsami.9b17137

125. Hu C, Cai L, Liu S, Liu Y, Zhou Y, Pang M. Copper-Doped Nanoscale Covalent Organic Polymer for Augmented Photo/Chemodynamic Synergistic Therapy and Immunotherapy. Bioconjug Chem (2020) 31 (6):1661-70. doi: 10.1021/acs.bioconjchem.0c00209

126. Chen L, Zhou L, Wang C, Han Y, Lu Y, Liu J, et al. Tumor-Targeted Drug and CpG Delivery System for Phototherapy and Docetaxel-Enhanced Immunotherapy with Polarization toward M1-Type Macrophages on Triple Negative Breast Cancers. Adv Mater (2019) 31(52):e1904997. doi: 10.1002/adma.201904997

127. Kleef R, Moss R, Szasz AM, Bohdjalian A, Bojar H, Bakacs T. Complete Clinical Remission of Stage IV Triple-Negative Breast Cancer Lung Metastasis Administering Low-Dose Immune Checkpoint Blockade in Combination With Hyperthermia and Interleukin-2. Integr Cancer Ther (2018) 17(4):1297-303. doi: 10.1177/1534735418794867

128. Oei AL, Korangath P, Mulka K, Helenius M, Coulter JB, Stewart J, et al. Enhancing the abscopal effect of radiation and immune checkpoint inhibitor therapies with magnetic nanoparticle hyperthermia in a model of metastatic breast cancer. Int $J$ Hyperthermia (2019) 36(sup1):47-63. doi: 10.1080/02656736.2019.1685686

129. Yin J, Dong J, Gao W, Wang Y. A case report of remarkable response to association of radiofrequency ablation with subsequent Atezolizumab in stage IV nonsmall cell lung cancer. Med (Baltimore) (2018) 97(44):e13112. doi: 10.1097/MD.0000000000013112

130. Datta NR, Ordonez SG, Gaipl US, Paulides MM, Crezee H, Gellermann J, et al. Local hyperthermia combined with radiotherapy and-/or 
chemotherapy: recent advances and promises for the future. Cancer Treat $\operatorname{Rev}(2015)$ 41(9):742-53. doi: 10.1016/j.ctrv.2015.05.009

131. Datta NR, Kok HP, Crezee H, Gaipl US, Bodis S. Integrating Loco-Regional Hyperthermia Into the Current Oncology Practice: SWOT and TOWS Analyses. Front Oncol (2020) 10:819. doi: 10.3389/fonc.2020.00819

132. Bordonaro M, Shirasawa S, Lazarova DL. In Hyperthermia Increased ERK and WNT Signaling Suppress Colorectal Cancer Cell Growth. Cancers (Basel) (2016) 8(5). doi: 10.3390/cancers 8050049

133. Milani V, Noessner E. Effects of thermal stress on tumor antigenicity and recognition by immune effector cells. Cancer Immunol Immunother (2006) 55(3):312-9. doi: 10.1007/s00262-005-0052-3
Conflict of Interest: The authors declare that the research was conducted in the absence of any commercial or financial relationships that could be construed as a potential conflict of interest.

Copyright $\odot 2020 \mathrm{Li}$, Deng, Sun and Ma. This is an open-access article distributed under the terms of the Creative Commons Attribution License (CC BY). The use, distribution or reproduction in other forums is permitted, provided the original author(s) and the copyright owner(s) are credited and that the original publication in this journal is cited, in accordance with accepted academic practice. No use, distribution or reproduction is permitted which does not comply with these terms. 